\title{
Конец правления династии Романовых в 1917 году в восприятии Л. Н. Андреева
}

\section{The Fall of the Romanov Dynasty in 1917 in the Perception of L. N. Andreev}

Йозеф Догнал

(Брно, Чехия; Трнава, Словакия)

\section{Абстракт:}

В статье сосредотачивается внимание на отзыве Л.Н. Андреева о конце правления династии Романовых. Андреев, усмотрев в этом историческом по своему значению событии коренной перелом обстановки в России, вносит в анализируемые публицистические тексты, напечатанные в газете «Русская воля» свои представления о мессианской по сути роли русской армии. Именно она призвана, по его мнению, стать во главе революции, которая освободит не только Германию, но все европейские народы и приведет к созданию государства, состоящего из объединенных европейских народов. К сожалению, такое видение оказалось неправильным, так как описывало скорее желаемое, а не реальное состояние и русской армии, и русского «народа».

\section{Ключевые слова:}

Л. Н. Андреев; публицистика 1917 года; падение династии Романовых; революция; мессианизм русской армии

\section{Abstract:}

The article focuses on the response of L. N. Andreev about the end of the Romanov dynasty. Andreev, perceiving in this historical event a radical breakdown of the

1 Tento příspěvek byl připraven $\mathrm{v}$ rámci plnění projektu specifického výzkumu Ústavu slavistiky Filozofické fakulty Masarykovy univerzity MUNI/A/1331/2020 Mezislovanské kulturní a literární vazby. 
situation in Russia, introduces into the analyzed journalistic texts printed in the newspaper Russkaya Volya his ideas about the essentially messianic role of the Russian army. It is the Russian army that, in his opinion, should lead the revolution, which will liberate not only Germany, but all European nations and lead to the creation of a state consisting of the united European nations. Unfortunately, such a vision of the army turned out to be incorrect, as it described the desired rather than the real state of both the Russian army and the Russian "nation".

\section{Key words:}

L. N. Andreev, Andreev's journalism of 1917, fall of the Romanov dynasty, revolution, messianism of Russian army

Прерывные единиць, такие как истории, возникают исключительно в сознании субъекта, которым определяются в непрерывном течении начало и конец. Это субъект делает в соответствии со своими ценностными установками. ${ }^{2}$

Художественная литература - это область специфической «переработки» того, что можно обозначить понятием реальная жизнь или же объективная реальность. Так как каждому индивиду она дается только в качестве или им субъективно переживаемой смены ситуаций текущего настоящего, или всяческих нарративов, которые ему приподносят то официальные (учебники, массмедии...), то неофициальные (друзья, соцсети...) источники, то очень затруднительным является ответ на вопрос о том, насколько можно считать художественную литературу чем-нибудь другим, чем фиктивным изображением субьективного восприятия определенных, конкретному субъекту (= автору) доступных импульсов, прошедших отбор на основе разных критериев (ценностного, идеологического, эстетического...) и переработанных его воображением в согласии с определенными установками на содержательную и формальную сторону сообщаемого. Существует, однако, промежуточная область между художественной литературой и беспристрастным, «объективным» извещением о фактах , т.е. область, позволяющая отозваться на факты (в данном случае на актуальные события), но в то же самое время содержащая и субъективность авторской позиции - публицистика. Именно

2 ŠMID, V.: Istorija literatury s točki zrenija narratologii. Voprosy literatury, 2012, № 5, s. 160. 
на публицистические тексты мы хотели бы направить наше внимание в этой небольшой статье, посвященной двум текстам Л. Н. Андреева самого начала 1917 года.

Первый из данных текстов - «Перед задачами времени» - был опубликован в самом начале 1917 года, 1-го января, в «Русской воле», газете, публикуемой с 15-го декабря 1916 года, в редакции которой Андреев заведовал литературным отделением. В этом тексте он упрекает русскую литературу, а именно русских писателей-современников, в неспособности отражать то, что, по его мнению, происходит в качестве чрезвычайно важного изменения не только в русской общеественной жизни - резкий поворот от «безмолствующих» народов к народам активным, возбужденным войнами и революционными вспышками, с ними связанными. Он упрекает как раз русских писателей, замечая: «Индивидуалистическая, очень сильная в вопросах личности, ее переживаний, психологии и морали, она слишком и не без опасения привыкла к „безмолствующему“ народу, чтобы сразу смело подойти к новому герою с его массовой психологией, массовой волей и доселе еще невиданными проявлениями последней в войнах и революциях.» ${ }^{3}$ Основную причину Андреев усматривает в ориентации русской литературы на прошлое, в том, что писатели слишком связаны с традицией 19 века, от которой, по его мнению, унаследовали «...ее ограниченный, почти кастовый „реализм“, тот что синицу в руках предпочитает журавлю в небе, и порою самым добросовестным образом смешивает себя с простой фотографией.» ${ }^{4} \mathrm{OH}$ замечает, что русской литературе не удалось пока «... дать широкую и общую картину совершающегося и могущего свершиться...» ${ }^{5}$, так что она стала ненужной читателю. В конце текста Андреев утверждает: «... если сейчас воюют солдаты, то после войны, когда начнется великое разрушение и великое строительство жизни, в тогдашние окопы придется идти - литераторам, мыслителям, художникам.» ${ }^{6}$ В связи с этим он ствит и вопрос: способны ли русские писатели внести их «... посильную лепту в мировую, тяжкую и бесконечно радостную работу?» ${ }^{7}$

Для Андреева это отчасти и вопрос о том, насколько он сам способен продолжать свою литературную работу и в каком именно направлении, так как «созидательный», направленный на будущее пафос его выступления не совсем

3 ANDREJEV, L.: Pered zadačami vremeni. In: ANDREJEV, L.: «Vernite Rossiju!». Moskva: Moskovskij rabočij, 1994, s. 70 .

4 Ibidem.

5 Ibidem.

6 Ibidem, c. 72.

7 Ibidem. 
отвечает его далеко не оптимистическим и не направленным на «народную душу» произведениям. Определенные черты интереса к «психологии массы» можно усмотреть уже в его романе «Сашка Жегулев». Кажется, однако, что именно война и ее последствия оказали на взгляды писателя сильное влияние, доказательством чего может служить его повесть «Иго войны» (1916), в которой герой сталкивается с народным протестом против обнищания и войны, чувствуя в демонстрирующих что-то новое, более мощное, хотя оба произведения сохраняют скорее пессимистический взгляд на будущее. Факт пробуждения большего интереса писателя к общественной жизни и политическим вопросам с начала Первой мировой войны констатирует Ю. Л. Епанчин: «Мысли о судьбе русского народа, о его грядущем пробуждении непрерывно мучили Леонида Андреева накануне мировой войны.» ${ }^{8}$ Пройденный жизненный опыт и опыт трех годов войны как будто усиливает в писателе на рубеже 1916-1917 гг. убеждение, касающееся мировой войны, о котором он напоминает в тексте «Перед задачами времени»; он убежден, что «... только пишется „война“, а выговаривается многими совсем иначе...» ${ }^{9}$ Примечательно, что это высказывание намекает на слово «революция», которое совсем не характерно для Андреева; ведь он чаще всего говорит о террористах, а не о революционерах - достаточно вспомнить и «Рассказ о семи повешенных» (1908), и многими отвергнутый рассказ «Тьма» (1907). Все выше упомянутое свидетельствует о повышенной активизации Андреева, о сдвиге в его воззрении, которое в его публицистике постепенно выкристаллизовывалось.

Радикальным шагом в этом направлении стало переломное событие, ускорившее мысли писателя о том, что предстоит и русской литературе, и русскому обществу как целому: конец царской власти в конце февраля по старому стилю / половине марта 1917 г. В утреннем выпуске газеты «Русская воля» была напечатана статья «Путь красных знамен» ${ }^{10}$ - отзыв Андреева на это историческое событие. Традиционная эмоциональность писателя нашла выражение в самом начале этого текста в злобном выпаде против Николая II, представителя Романовых. По его мнению, которое Андреев не мог раньше открыто выражать, Романовы «Глухие к доводам совести и блага народного, почти безумные в поступках, трагически лишенные даже чувства самосохранения, они - или он - с великим наслаждением перестреляли

8 JEPANČIN, J. L.: Apologet vojny ili duchovnyj revoljucioner? Pozicija L. N. Andrejeva v gody Pervoj mirovoj vojny. <https://www.sgu.ru/archive/old.sgu.ru/files/nodes/9873/o8.pdf>. [online]. [cit. 17. 4. 2021].

9 ANDREJEV, L.: Pered zadačami vremeni. In: ANDREJEV, L.: «Vernite Rossiju!». Moskva: Moskovskij rabočij, 1994, s. 69-70.

10 ANDREJEV, L.: Put' krasnych znamen. In: Russkala Volja, No. 4, 8 marta 1917, s. 2. 
и перевешали бы нас всех, оставайся в их власти пулеметы и пушки. Пусть вся Россия превратится в кладбище, они согласны царствовать и над кладбищем.» ${ }^{11}$ Ссылка на народное благо как будто подхватывает именно мысль о заговорившем народе из январского текста. Упор именно на народ в тексте продолжается, когда Андреев утверждает, что «... пулеметы и пушки оказались в руках народа, ибо та армия, что ныне вся ходит под красными знаменами, есть не что иное, как сам русский народ, только в о о р у ж е н н ы й.» ${ }^{12}$ (разрядка Л.Н. Андреев), по отношению к которому «... Романов немедленно превратился в одинокого, бессильного и жалкого человека.» ${ }^{13}$

В рамках понятия народа Андреев подчеркивает роль армии, которая как защитник и представитель народа имеет почетное право состоять в «Совете Рабочих Депутатов» и которой он посвящает в тексте специальное внимание в связи с убеждением, что посредством армии «... вот уже год или полтора войну ведет исключительно народ, и борется он не за самодержавие, не за царя, а за Россию, т. е. за самих себя.» ${ }^{14}$ Андреев этот тезис, исходящий из его восхищения произошедшим и из определенного незнания действительного положения дел в той самой армии, из довольно наивного представления о патриотизме как основном мотиве, которым руководствуются солдаты на фронте, развивает в утверждении, что в момент отречения царя от правления армия превратилась в армию «... добровольцев, свободных граждан России, с ружьем в руках отстаивающих свою свободу и права. Если до 27 февраля могло казаться, что нашу армию удерживает на фронте только дисциплина, то теперь видно будет всем, что ее удерживает другое: любовь к своему народу, любовь к свободе и вера в грядущее братство.» 15

Андреев, развивая свою мысль, опять - как и в первом нами упоминаемом тексте - возвращается к началу войны и записи в своем дневнике от 1914 года, которую он на этот раз дополняет и расширяет: «Э т о только пишется „война“, а называется р е в о л ю ц и е й. В своем логическом развитии эта „война“ приведет нас к свержению Романовых и закончится не обычным путем всех ранее бьющих войн, а европейской революцией. В свою очередь эта европейская революция приведет к уничтожению милитаризма, т. е. постоянных армий

11 ANDREJEV, L.: Put' krasnych znamen. In: ANDREJEV, L.: Pered zadačami vremeni. Političeskije stat'ji 1917-1919 godov. Sostavlenije i podgotovka teksta Ričarda Dèvisa. Benson: Chalidze Publications 1985 , p. 18.

12 Ibidem.

13 Ibidem.

14 Ibidem, p. 20.

15 Ibidem, p. 20-21. 
ик созданию ев ропейских соединенных ш татов». ${ }^{16}$ (разрядка - Л.Н. Андреев) Андреев, как показывает текст, прямо восхищен тем, что сбылась его мечта о свержении Романовых, так что он извлекает из этого факта и убеждение, что сбывается и его мысль о внезапном пришествии революции после такого исторического события. Именно эмоционально возбужденное чувство радости оправдания его предчувствий приводит его к дальнейшим рассуждениям - на этот раз чисто умозрительным - о будущем, в которые он вносит фальшивое прямолинейное умозаключение: так как выполнилось желание о падении Романовых, началась революция; и так как началась революция, произойдет и создание европейских соединенных штатов, разумеется, тоже прошедших через революцию. Андреев как раз в этом месте текста переходит от осмысления исторического события к конструированию последующих действий, от исторического момента к умозрительному, телеологически направленному описанию действий, осуществление которых далеко не гарантировано, тем более неправдоподобным явялется им предполагаемая их прямолинейность. Из области реального переходит писатель в область желаемого, прогнозируемого, т. е., по сути, в сферу фантазии.

Неудивительно, что так же прямолинейно решает Андреев и вопрос о том, кто будет провозвестником нового европейского порядка - им станет Россия и ее армия: «Ныне дом Романовых рухнул, и Россия свободна. Но это лишь первый, хотя и чрезвычайно важный этап на пути войны-революции. Революция должна идти дальше - и пойдет! - и не за горами тот день, когда рухнет и дом Гогенцоллернов, и мир будут заключать свободные народы на основах свободы, равенства и братства.» ${ }^{17}$ (курсив - Л.Н. Андреев) Первой страной, в которой, по Андрееву, произойдет то же самое освобождение от угнетения народа, должна стать Германия: «... приблизить этот день - день революции в Берлине - вот ближайшая задача русских революционных войск, осуществимая лишь при победе над германскими цезарскими войсками. [...] Германские, ныне цезарские войска должны быть побеждены русской армией для торжества революционных начал в Берлине, - в этом заключается великая и благороднейшая задача нашей свободной России.» ${ }^{18}$ Прямо опьяневший от своих мыслей и не ознакомленный достаточно с ситуацией и в армии как таковой, и на фронтах, и с положением в немецкой армии, Андреев забывает о действительном положении в России и преподносит читателю свое убеждение в мессианской роли русского народа: «Революционная

16 Ibidem, p. 21-22.

17 Ibidem, p. 23.

18 Ibidem, p. 25-26. 
Россия, свергшая тиранический гнет, стоит на фронте перед все той же рабской, феодальной Германией и на красных знаменах своих несет ей не новую иноземную тиранию, а свободу, равенство и братство!» ${ }^{19}$ Само собой разумеется, что основную роль на себя должна взять, по представлениям писателя, русская армия: «... молодая русская революционная армия должна поднять на свои плечи свободу народов и, не сгибаясь, нести ее в мир. Великая задача, благородная задача! Ибо осуществление ее несет новую жизнь всей старой Европе. [...] К оружию, граждане! Формируйте ваши батальоны! Вперед! Вперед!» 20

Восхищенный призыв к победе над Германией как к ключевой задаче русской армии подкрепляется рядом априорных утверждений Андреева, никак не основанных на основном анализе реального состояния - все его представления вытекают из чистого идеализма, из неистовой радости единственного, хотя по своему значению исторического, события, из исчезновения царской власти. Иначе нельзя было бы ему утверждать, что: «Только а р м и я, т. е. дисциплина, только революция, т. е. народ, проникнутый чувством свободы, может победить цезарские войска Вильгельма и принести Европе мир и свободу.» ${ }^{21}$ (разрядка Л.Н. Андреева) Нельзя было бы убеждать читателей в том, что вдруг, в один день, всё в армии и в обществе изменилось настолько, что можно верить его тезису, по которому «У нас нет отныне солдатчины. У нас есть вооруженный русский народ, который выполняет дело защиты родины и свободы и, выполнив его, превратится в простых граждан.» 22

Текст заканчиватся патетичным призывом Андреева к русским солдатам: «По всему фронту, обращенному к немцам, широко разверните красные победные знамена: пусть знает отныне всякий стреляющий германец, что стреляет он - в свободу! И под священным знаком красных знамен несите [мир] и свободу порабощенным народам!» 23

Оба текста по своей структуре тождественны: оба они относятся к ясно определенной точке на временной оси, оба отражают с данной временной точки прошедшее и, отталкиваясь от его негативной оценки, проецируют будущее. Оба текста соединяет и ключевое слово: «народ». И кажется, что Андреев допускает ту же ошибку, которую допускали уже почти полвека тому назад русские народники, предполагающие, что «народ» - это однородная,

\footnotetext{
19 Ibidem, p. 26.

20 Ibidem, p. 27.

21 Ibidem, p. 29.

22 Ibidem.

23 Ibidem, p. 30.
} 
тем же способом мыслящая, действующая и разделяющая те же цели и идеалы (т. е. по сути цели и идеалы народников) сплоченная масса, так что «народом» ему представляются все за исключением царя и самых ему близких людей.

Даже при условии, что так могло в военную пору показаться, именно тут чувствуется противоречие между Андреевым-писателем и Андреевым-публицистом: первый умеет точно отобразить индивида, его специфический склад души, именно для него характерное поведение, умеет уловить и обманчивые, внутренне противоречивые моменты эмоционального возбуждения; Андреев-публицист как будто именно об этом забывает: он отождествляет «народ» со своими идеальными представлениями о нем. Таким же идеальным образом он представляет себе и армию, т. е. ту часть «народа», которой он присуждает роль и защитника Родины, и спасителя не только России, но всей Европы. Мессианизм, который трудно было бы уловить в его художественных произведениях, вырывается наружу и в его понимании «народа», и в его желании, чтобы российская революция вылилась/претворилась в общеевропейскую. Именно в представлении о европейских масштабах революционного сдвига Андреев близок и марксистам, целью которых было разжечь именно общее, по сути мировое движение, неограничивающееся никакой границей.

О субъективности рассуждений писателя свидетельствует и тот факт, что в обеих статьях нет никаких конкретных аргументов, с помощью которых он смог бы доказать свою правоту. Цитата из его дневника - это не доказательство, а лишь факт того, что он, кажется, тонко ощущал громадное значение только что начавшегося в 1914 году военного столкновения. Именно его рассказы, романы и драмы достаточно часто показывают, насколько непрочны все кажущиеся основными «нормы» поведения и индивида, и группы, а в публицистике он об этом совсем забывает.

Самому Андрееву предстояло очень рано убедиться в том, что его достаточно наивные чаяния несбыточны: он скоро столкнулся с фактами о «народе» и о действительной морали армии. Уже в мае, в той же «Русской воле», он так же эмоционально, как встречал «народ» в марте, вспоминает Некрасова и в тексте «И снова рыцари на час» спрашивает о том, куда этот «народ» делся: «... где же эти люди, - те, те, что сделали эту чудесную бескровную, весь мир поразившую, светлую революцию? Их было много - весь народ. Да, только весь народ всею своей неизмеримой силой мог одним толчком сдвинуть гору. Где он? Или весь он - только рыцарь на час?» ${ }^{24}$ Разочаровавшийся в «народе», он еще глубже разочаровывается чуть позже в армии, когда под

24 ANDREJEV, L.: I snova rycari na čas. In: ANDREJEV, L.: Pered zadačami vremeni. Političeskije stat'ji 1917-1919 godov. Sostavlenije i podgotovka teksta Ričarda Dèvisa. Benson: Chalidze Publications 1985, p. 94 . 
влиянием актуальных событий в июле сочиняет и в той же газете печатает совсем по-другому звучащий текст «К тебе, солдат!» Но это - прозревший, когда-то, совсем недавно, восхищенный моментом публицист, это уже опять Андреев, заглядывающий глубже и нашедший по окончанию моментальной эйфории то, что он всегда умел своим чутьем ощутить: неоднозначность, опасность, темное не только в индивиде, но и в «народе» и в наступающей в решительную атаку идеологии.

\section{Литература:}

ANDREJEV, L.: I snova rycari na čas. In: ANDREJEV, L.: Pered zadačami vremeni. Političeskije stat'ji 1917-1919 godov. Sostavlenije i podgotovka teksta Ričarda Dèvisa. Benson: Chalidze Publications 1985, s. 18-30.

ANDREJEV, L.: Pered zadačami vremeni. In: ANDREJEV, L.: «Vernite Rossiju!». Moskva: Moskovskij rabočij, 1994, s. 69-72. ISBN 5-239-01556-2.

ANDREJEV, L.: Put' krasnych znamen. In: ANDREJEV, L.: Pered zadačami vremeni. Političeskije stat'ji 1917-1919 godov. Sostavlenije i podgotovka teksta Ričarda Dèvisa. Benson: Chalidze Publications 1985, ss. 18-30.

JEPANČIN, J. L.: Apologet vojny ili duchovnyj revoljucioner? Pozicija L. N. Andrejeva $v$ gody Pervoj mirovoj vojny. <https://www.sgu.ru/archive/old.sgu.ru/files/nodes/ 9873/o8.pdf>. [online]. [cit. 17. 4. 2021].

ŠMID, V.: Istorija literatury s točki zrenija narratologii. Voprosy literatury, 2012, № 5, S. $157-174$.

\section{About the author \\ Josef Dohnal \\ Masaryk University Brno, Faculty of Arts, Department of Slavonic Studies, Brno, Czech Republic \\ University of Ss. Cyril and Methodius in Trnava, Faculty of Arts, Department of Russian Language, Trnava, Slovak Republic \\ josef-dohnal@volny.cz \\ https://orcid.org/0000-0002-0763-5784}

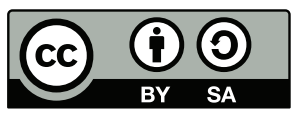

This work can be used in accordance with the Creative Commons BY-SA 4.0 International license terms and conditions (<https://creativecommons.org/licenses/by-sa/4.0/legalcode>). This does not apply to works or elements (such as images or photographs) that are used in the work under a contractual license or exception or limitation to relevant rights. 
